\title{
The Challenges Ahead
}

\author{
Michael J. Fogarty \\ NOAA/National Marine Fisheries Service. Woods Hole, Massachusetts USA
}

Extracting the broader lessons concerning climate impacts on marine ecosystems from regional studies in the Northwest Atlantic, Northeast Pacific, and Southern Ocean will be the central challenge facing U.S. GLOBEC researchers as field work is completed and synthesis efforts within each region are undertaken. U.S. GLOBEC process studies will be completed in 2002 in the California Current System and in the Southern Ocean, and in 2003 in the Coastal Gulf of Alaska. Synthesis efforts are now underway for the Georges Bank program and will be initiated in the Northeast Pacific and Southern Ocean programs following completion of field efforts (Figure 1). A higher-order synthesis effort incorporating basin-scale modeling efforts and comparative analyses among U.S. GLOBEC studies and related programs is then planned to meet the overarching GLOBEC goal of predicting the effects of global climate change on marine ecosystems.

Models provide the principal vehicle for synthesis and integration of GLOBEC process, observational, and retrospective studies. Prediction of climateimpacts on marine ecosystems involves a fundamental challenge in effectively linking biological/ecological, hydrodynamic, and climate models (Figure 2). Models spanning a broad range of mechanistic detail and spatio-temporal scales have been employed in U.S. GLOBEC studies. Biological/ecological models ranging from individual-based and stage-structured population models to simple N-P-Z-F (NutrientPhytoplankton-Zooplankton-Fish) ecosystem models have been linked to regional scale hydrodynamic models to explore the implications of climate variability and change. It remains to expand the focus of these modeling efforts to encompass basin-scale processes. To effectively predict population and ecosystem trajectories it will be further necessary to utilize coupled climate models to drive the biological/ecological models. The ability to span multiple scales of space and time in these modeling efforts is central to the success of the overall effort. Scaling up from process studies through broad or mesoscale observational programs and retrospective analysis of extensive time series records is an essential component of this overall effort. Because General Circulation Models (GCMs) currently employ levels of spatial resolution coarser than many of the mesoscale and finer scale physical oceanographic and population processes considered in GLOBEC studies, the linkage with climate models will necessarily entail consideration of appropriate methods of down-scaling. Linking predicted changes at the scales represented by the GCMs to the local and regional scales of processes relevant to GLOBEC research is essential.

U.S. GLOBEC study sites have been selected to address specific physical processes and target species likely to be affected by climate change. From its inception, the importance of comparative analysis in U.S. GLOBEC for ascertaining the effects of climate forcing has been recognized. Critical questions addressed in GLOBEC studies include "how does variability in populations of the target taxa differ under different physical processes and system types and how does climate change influence this process?" Comparison of the dynamics of closely related taxa selected as target species in relation to specific physical processes (including stratification, mechanisms of retention and loss, upwelling and downwelling, and cross-front exchange) will be an integral component of the overall synthesis and integration effort in U.S. GLOBEC (Table 1). Comparisons of closely related species within regions (e.g Calanus and Pseudocalanus on Georges Bank, coho and chinook salmon in the California Current; euphausiids of the genera Euphausia and Thysanonessa in the Gulf of Alaska) in relation to these physical processes will also be employed in conjunction with comparisons across system types to examine the effects of climate forcing.

As U.S. GLOBEC studies have progressed, it has become evident that factors such as top-down vs. bottom-up controls on productivity, and the importance of topographic controls on local and regional circulation patterns provide important cross-cutting themes and foci for comparative analysis. Bottom-up controls mediated through mechanisms of nutrient exchange have been hypothesized to be critically important in the California Current System and the Coastal Gulf of Alaska and related to the apparent inverse production regimes for salmon in these regions. In contrast, topdown controls by predators on the target species may be of central importance in the Southern Ocean and on Georges Bank. In the former, the relatively simple food 


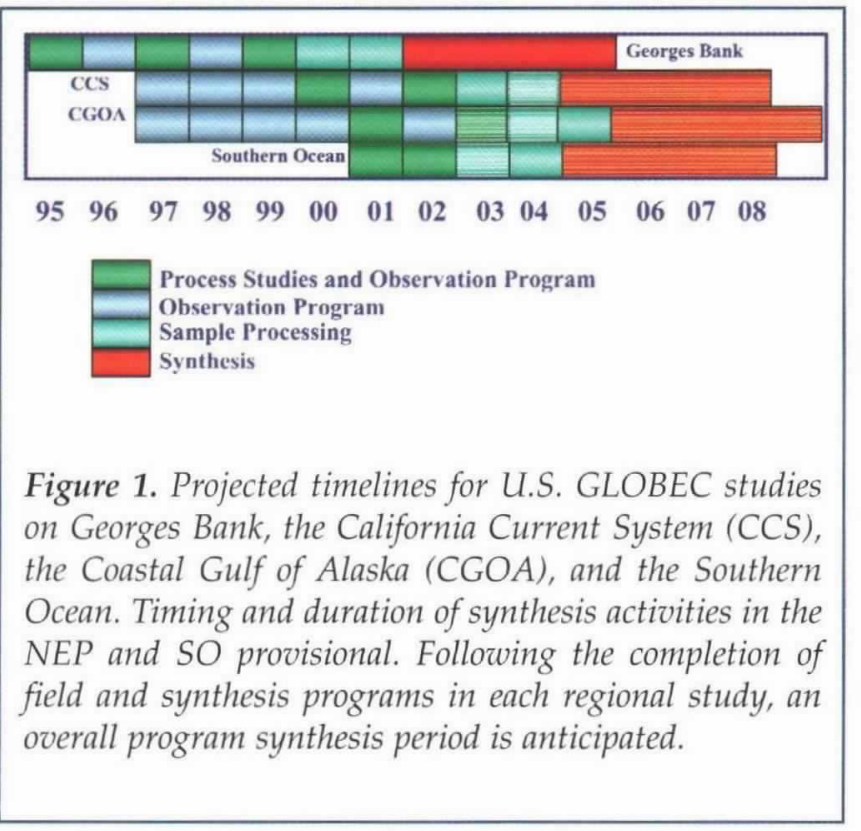

web results in strong trophic linkages, while in the latter the direct and indirect effects of overharvesting have resulted in dramatic changes in community composition. Planktivorous fishes are currently at high levels of abundance in this system; these species prey on copepods and larval fish. Retentive circulation features associated with the local topography have emerged as key features in each of the U.S. GLOBEC study sites. Comparisons of levels of population variability in retentive vs. advective systems and subsystems will provide important insights into the population dynamics of the target species.

Consideration of the effects of climate forcing on the major system types represented in U.S. GLOBEC

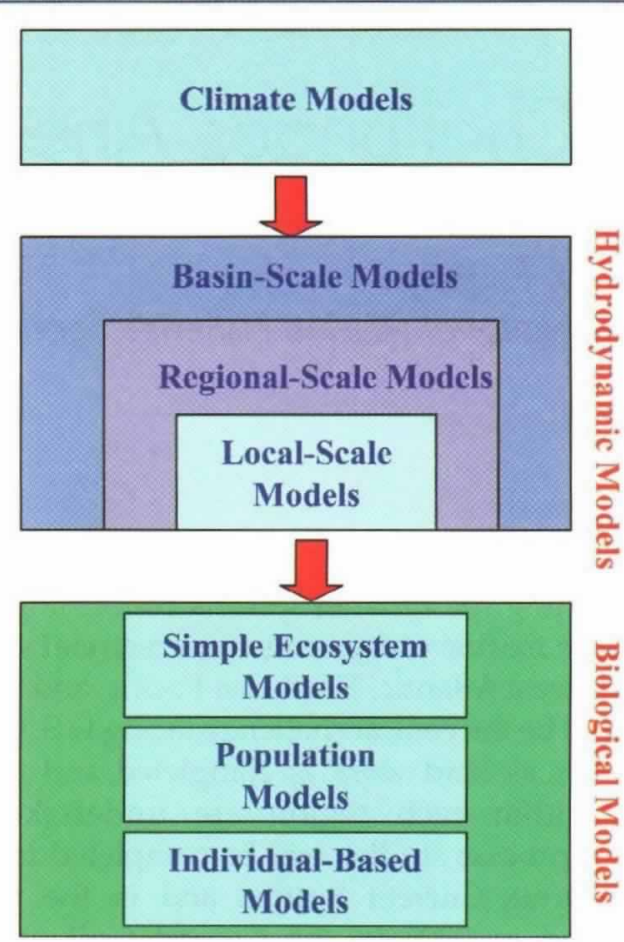

Figure 2. Linkage of biological/ecological, hydrodynamic, and climate models required for synthesis and integration in U.S. GLOBEC. Biological models employed include individual-based models, population-based models, and simple ecosystem models. Nested hydrodynamic models at the local, regional, and basin scales are under development. Linkage to general circulation models has not yet been attempted in U.S. GLOBEC studies.

Table 1. The dynamics of target taxa in U.S. GLOBEC studies with respect to key physical processes can be compared in one or more GLOBEC regional programs: Georges Bank (GB), California current systems (CCS), Coastal Gulf of Alaska (CGOA) and Southern Ocean (SO). Regional program sites marked by an asterisk afford opportunities for comparisons among the principal target taxa within the region.

\section{Physical Process}

\begin{tabular}{|l|l|l|l|l|}
\hline Taxa & Stratification & Retention/Loss & $\begin{array}{l}\text { Upwelling/ing } \\
\text { Downwelling }\end{array}$ & $\begin{array}{l}\text { Cross-Shelf } \\
\text { Transport }\end{array}$ \\
\hline $\begin{array}{l}\text { Calanoid } \\
\text { Copepods }\end{array}$ & $G B^{*} / C C S^{*} / C G O A^{*}$ & $G B^{*} / C C S^{*} / C G O A^{*}$ & $C C S^{*} / C G O A^{*}$ & $C C S^{*} / C G O A^{*}$ \\
\hline Euphausiids & $C C S^{*} / C G O A^{*} / S O$ & $C C S^{*} / C G O A^{*} / S O$ & $C C S^{*} / C G O A^{*}$ & $C C S^{*} / C G O A^{*}$ \\
\hline Gadoids & $G B^{*}$ & $G B^{*}$ & & \\
\hline Salmonids & $C C S^{*} / C G O A$ & & $C C S^{*} / C G O A$ & $C C S^{*} / C G O A$ \\
\hline
\end{tabular}


will require comparisons not only among the regional U.S. studies but comparisons and contrasts with results from related national and international programs. The worldwide GLOBEC research effort affords critical opportunities for comparative analyses and for consideration of basin-scale processes. In particular, comparisons with GLOBEC Canada studies of calanoid copepods and gadoids on bank and shelf systems in the Atlantic and copepods, euphausiids, and salmonids in the Pacific will be critical. Basin-scale comparisons of direct relevance to U.S. GLOBEC will be possible through programs such as the ICES Cod and Climate Change Program and the PICES Climate Change and Carrying Capacity Program; both are designated regional programs of International GLOBEC.

Meeting the challenge of understanding and predicting the effects of global climate change on marine ecosystems is essential to effective stewardship of the marine environment and living marine resources. The steadily increasing demand for protein from the sea related to the burgeoning human population and the recognized health benefits of seafood consumption have placed unprecedented stress on these systems. It is essential that the potential synergistic interactions of climate change effects on marine ecosystems and other anthropogenic impacts be fully evaluated and integrated into management strategies and mitigation plans.

This is U.S. GLOBEC contribution Number 236.
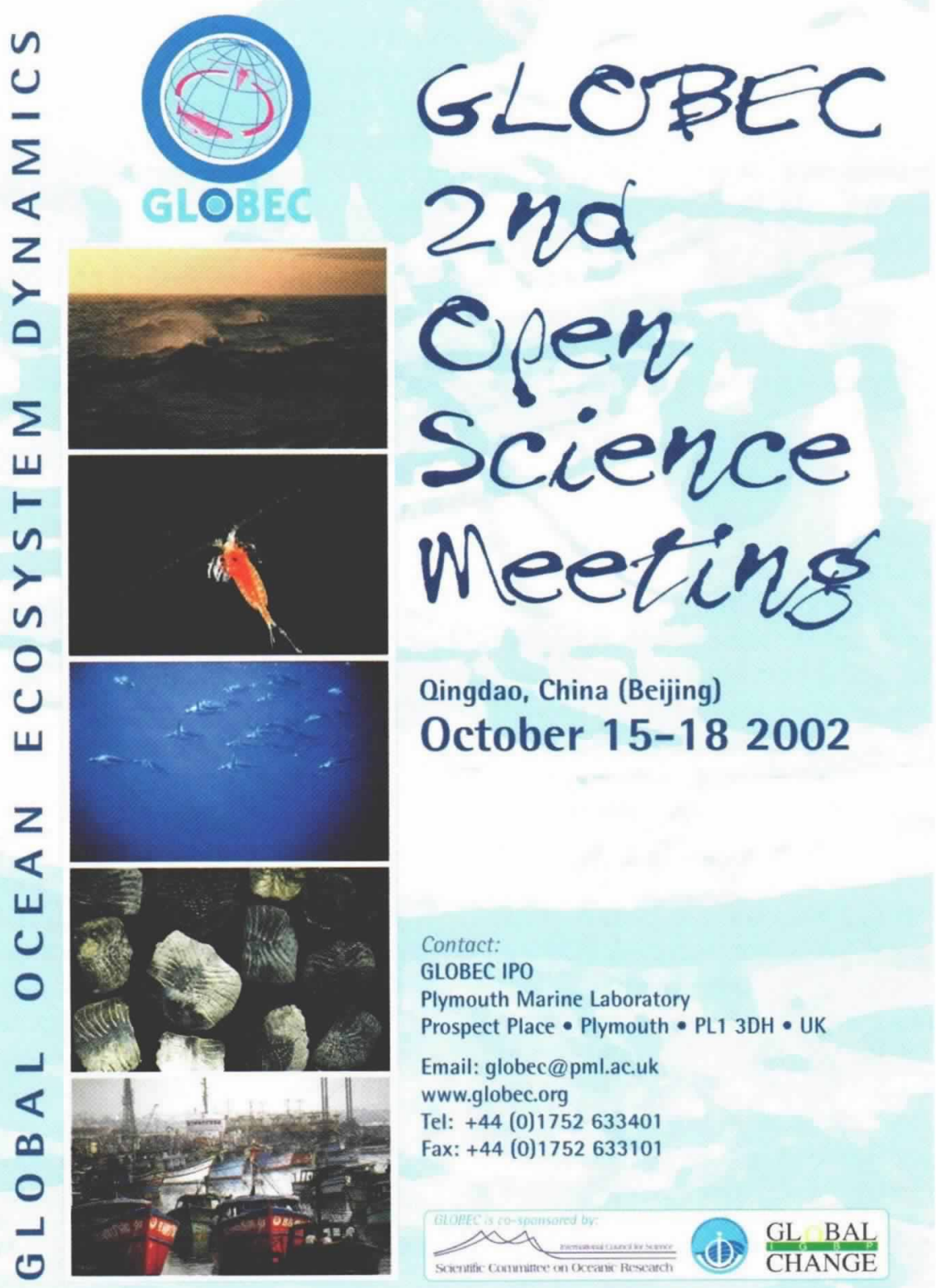

Contact:

GLOBEC IPO

Plymouth Marine Laboratory

Prospect Place • Plymouth • PL1 3DH • UK

Email: globec@pml.ac.uk

www.globec.org

Tel: $+44(0) 1752633401$

Fax: $+44(0) 1752633101$

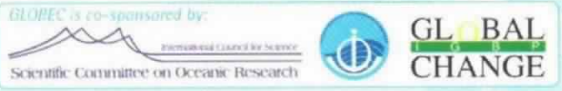

